\title{
YouTube as a Source of Patient Information for Bipolar Disorder: A Content-Quality and Optimization Analysis
}

Tomasz Szmuda

Gdanski Uniwersytet Medyczny

Weronika Magdalena Żydowicz ( $\nabla$ veronikazydowicz@wp.pl )

Gdanski Uniwersytet Medyczny https://orcid.org/0000-0002-5827-3736

Shan Ali

Gdanski Uniwersytet Medyczny

Karolina Fedorow

Gdanski Uniwersytet Medyczny

Paweł Słoniewski

Gdanski Uniwersytet Medyczny

Research

Keywords: bipolar disorder, Internet, online, psychiatry, YouTube

Posted Date: May 28th, 2020

DOI: https://doi.org/10.21203/rs.3.rs-31091/v1

License: (c) (1) This work is licensed under a Creative Commons Attribution 4.0 International License. Read Full License 


\section{Abstract}

Background YouTube is currently the second most popular website in the world and it is often used by patients to access health information online. Our aim was to evaluate the content-quality of YouTube videos relating to bipolar disorder.

Methods We chose the first 30 videos for four different search phrases: "bipolar disorder," "bipolar disorder treatment," "bipolar disorder symptoms" and "manic depression." Video contents were evaluated by two independent final year medical students using the validated DISCERN instrument. Qualitative data, quantitative data and the upload source was recorded for analysis.

Results Out of the total 120 videos, 80 videos met our inclusion criteria and were evaluated. The mean DISCERN score was 63.5 (out of 75 possible points). This indicates that the quality of YouTube videos on bipolar disorder is excellent. Reliability between the two raters was excellent (intraclass correlation coefficient $=0.96)$. Nearly all videos had symptoms of the disorder $(100 \%)$ and the impact of the disorder on daily life (98.8\%). Videos were mostly uploaded by educational channels $(61.3 \%)$ and hospitals (16.3\%). Videos that had a doctor speaker had a significantly higher average daily views, comments and a video power index $(P<0.05)$.

Conclusions The quality of YouTube videos on bipolar disorder is good. We have included a list of the top-quality videos in our paper as they may be used by patients and physicians as a reference to find the most reliable videos for patient education. Having a doctor speaker in a video optimizes a video for higher audience engagement.

\section{Background}

Approximately 4.5 billion people are active internet users, this translates to $59 \%$ of the world population. (2020) YouTube is the most common platform for video viewing worldwide.(2020) The general public uses YouTube primarily as a source of entertainment but it has also expanded as a medium for education. $90 \%$ of people aged 18 to 24 years trust medical information shared by others online.(2012) YouTube's large volume of information and accessibility attracts doctors, medical students, patients, and their families to use it as a source of medical information. Healthcare-related videos published on YouTube are often not reliable and may contain misinformation.(Madathil et al. 2015; Szmuda et al. 2020b) While there have been studies regarding the role of YouTube videos disseminating psychoeducation for dementia, schizophrenia and narcolepsy, there are currently no studies pertaining to the quality of videos for bipolar disorder (BD).(Lam et al. 2017; Lam and Woo 2020; Szmuda et al. 2020a)

$\mathrm{BD}$ is a mental disorder characterized by shifts in mood and affect ranging from depression to mania. Bipolar I (BP1) is defined by prolonged periods of mania and depression, often requiring hospitalization. Bipolar II (BP2) is defined by cycles of hypomanic episodes and depression. It affects $1 \%$ of the population worldwide and the median age of onset is 25 years. ([CSL STYLE ERROR: reference with no printed form.]) It is found equally among men and women and it prevails in all social classes, races and 
ethnicities.([CSL STYLE ERROR: reference with no printed form.]) Individuals with BD consistently report social stigma as one of the greatest challenges of living with the condition and thus anonymously search for medical information online (rather than seeking professional help).(Mileva et al. 2013) For this reason, BD is often misdiagnosed or can go undiagnosed for up to 10 years which perpetuates the suffering from the disease.(Shen et al. 2018)

Our aim was to assess the current quality and the reliability of YouTube videos on BD using a comprehensive search strategy. We also sought to determine what optimizes a video for audience engagement.

\section{Materials And Methods}

\section{Search Strategy:}

We searched YouTube on November 11, 2019 using the four key phrases; "bipolar disorder", "bipolar disorder treatment", "bipolar disorder symptoms", and "manic depression". We felt that these search terms offered a sufficient view of BD videos because they are relative synonyms to BD. We intentionally chose these phrases since after being given a diagnosis of "bipolar disorder" we anticipated that a patient would probably use the same search term or a slight variation of it on YouTube.

\section{Data Collection:}

Previous research shows that $90 \%$ of search engine users only look at the first 3 pages of searched content. Thus, the first 30 results of each search were viewed and evaluated under the chosen criteria and results were recorded.(2006)

\section{Inclusion and Exclusion Criteria:}

Out of 116 videos, we evaluated a total of 80 videos related to BD. Any duplicates, advertisements, music videos, videos in another language or videos clearly not related to BD (e.g. music videos) were excluded.

\section{Variables Extracted:}

We used the Google Chrome extension "VidIQ Vision for YouTube" to retrieve quantitative information from each video. This included: total number of views, total number of comments, duration, video description word count, video description link count, referrers, likes, dislikes, and video tags and time since upload. Information about the host channel was also recorded: uploader name, average daily views, average daily subscribers, subscribers, and tags.

Qualitative information included: impact of the disorder on everyday life, symptoms of BD, personal story/vignette of person, difference between BP1 and BP2, results of treatment, discussion of prognosis, animations, diagrams, pathomechanisms explained, a doctor speaker and/or a patient experience. 
We recorded the source of upload and categorized them into either: physician, hospital, patient, educational or other.

\section{Scoring System:}

Videos were evaluated using the validated DISCERN instrument, by two medical students in the final clinical years of their studies who each had five years of experience using the DISCERN instrument. The DISCERN instrument is a sixteen-point questionnaire designed to allow lay-people to judge the reliability \& quality of health information as seen on Table 1.(Charnock et al. 1999; Rees et al. 2002) The first fifteen questions are scored on a scale from 1-5 depending on if they meet the given criteria. A score of 1 means the video definitely did not fulfill the criteria, partial fulfilment of criteria can be scored a 2-4 ranging on the independent judgement of the scorer, and a 5 is a definite yes. The total minimum score is 16 and the maximum score is 80 points.

\section{TABLE LEGENDS}




\begin{tabular}{|c|c|c|c|c|c|c|}
\hline 1 & Are the aims clear? & 1 & 2 & 3 & 4 & 5 \\
\hline 2 & Does it achieve its aims? & 1 & 2 & 3 & 4 & 5 \\
\hline 3 & Is it relevant? & 1 & 2 & 3 & 4 & 5 \\
\hline 4 & $\begin{array}{l}\text { Is it clear what sources of information were used to compile the } \\
\text { publication (other than the author or producer)? }\end{array}$ & 1 & 2 & 3 & 4 & 5 \\
\hline 5 & $\begin{array}{l}\text { Is it clear when the information used or reported in the publication } \\
\text { was produced? }\end{array}$ & 1 & 2 & 3 & 4 & 5 \\
\hline 6 & Is it balanced and unbiased? & 1 & 2 & 3 & 4 & 5 \\
\hline 7 & $\begin{array}{l}\text { Does it provide details of additional sources of support and } \\
\text { information? }\end{array}$ & 1 & 2 & 3 & 4 & 5 \\
\hline 8 & Does it refer to areas of uncertainty? & 1 & 2 & 3 & 4 & 5 \\
\hline 9 & Does it describe how each treatment works? & 1 & 2 & 3 & 4 & 5 \\
\hline 10 & Does it describe the benefits of each treatment? & 1 & 2 & 3 & 4 & 5 \\
\hline 11 & Does it describe the risks of each treatment? & 1 & 2 & 3 & 4 & 5 \\
\hline 12 & Does it describe what would happen if no treatment is used? & 1 & 2 & 3 & 4 & 5 \\
\hline 13 & $\begin{array}{l}\text { Does it describe how the treatment choices affect overall quality of } \\
\text { life? }\end{array}$ & 1 & 2 & 3 & 4 & 5 \\
\hline 14 & Is it clear that there may be more than 1 possible treatment choice? & 1 & 2 & 3 & 4 & 5 \\
\hline 15 & Does it provide support for shared decision making? & 1 & 2 & 3 & 4 & 5 \\
\hline 16 & $\begin{array}{l}\text { Based on the answers to all of these questions, rate the overall } \\
\text { quality of the publication as a source of information about } \\
\text { treatment choices }\end{array}$ & 1 & 2 & 3 & 4 & 5 \\
\hline
\end{tabular}

Table 1: The 16 question DISCERN Instrument

The last question is a summary of the previous 15 DISCERN questions and determines whether the publication can be used as an appropriate source of information. An overall rating of 2 or below indicates the publication is of "poor" quality with many shortcomings and is not useful or appropriate. A score of 3 indicates "fair" quality of publication that requires additional sources of information due to some limitations. A score of 4 or above indicates "good" quality meaning the publication is useful and appropriate as a source of information about treatment choices.(Charnock et al. 1999; Rees et al. 2002)

The DISCERN score may also be interpreted as a total out of 75 using only the first 15 questions. A score of 63 to 75 indicates an "excellent" score, 51 to 62 indicates a "good" score, 39 to 50 indicates a "fair" 
score, 27-38 indicates a "poor" score and 16 to 26 indicates a "very poor" score.(Cassidy and Baker 2016; Weil et al. 2014)

\section{Video Optimization:}

The optimization analysis method in this study is similar to a studies previously published.(Szmuda et al. 2020a; Szmuda et al. 2020b) The average daily views [total views/days since upload], the like ratio [(likes/likes +dislikes)*100] and the video power index (VPI) $[($ like*100/(like + dislike) $) \star($ views/day)/100] were used to assess the audience engagement with a video. Of note, standardized cut-off scores do not exist for the VPI since it depends on the number of likes and views and this is highly variable depending on how popular a video is. However, we have provided the mean VPI in the results section so that a reader may use it for reference (to see if a VPI value is higher or lower than the mean).

Videos were grouped based on their qualitative content (e.g. if a video included the treatment of BP disorder). These video groups were analyzed against their average daily views, like ratio, VPI and number of comments.

\section{Statistical Methods:}

Descriptive statistics for continuous variables covered mean, median, range and standard deviation. The Mann-Whitney $U$ test was used to find differences between categorical variables and the intraclass correlation coefficient was used to ascertain inter-rater agreement. $\mathrm{P}<0.05$ was deemed significant. Google Sheets (Google LLC, Mountain View, California, USA) was used for illustrations. Past (Hammer and Harper, Øyvind Hammer, Natural History Museum, University of Oslo) was used for statistical analysis.

\section{Results}

\section{Video Contents:}

A total of 80 unique videos were included in our content analysis. Figure 1 shows the qualitative content of videos about BD. Almost all videos covered the symptoms (100\%) and the impact (99\%) of BD on daily life. Most videos included the treatment (60\%), the prognosis (54\%), a personal vignette (54\%) and a patient experience concerning BD (51\%). However, most videos did not have: a doctor speaking (48\%), animation (28\%), BD pathomechanisms (25\%), a diagram (23\%), and the differences between BD1 \& BD2 (31\%).

\section{Video Upload Source:}


Figure 2 illustrates the source of the videos uploaded. The majority of the videos were uploaded by an educational channel 61.3\% (49 videos). The remainder of the videos were uploaded by a hospital 16.3\% (13 videos), a physician $11.3 \%$ (9 videos), a patient $8.8 \%$ (7 videos) and 2.5\% (2 videos) were uploaded by other sources.

\section{Video Statistics:}

The following represent the mean quantitative aspects of the videos overall: duration 1034.1 (47-7573) seconds, view count 323059 (1061-3500000), comments 702.3 (0-5960), likes 6011.4 (0-61000), dislikes 153.8 (0-1683), average daily views 41 (0-630), like ratio 93.9 (50-100), video referrers 71.7 (0-527) and days since upload 1459.325 (125-4294).

The following represent the mean channel popularity of the videos: subscribers 1713569 (321700000), daily views 6824841.4 (49.8-486900000) and daily subscribers 39832.6 (0.11550000).

\section{Video Quality Evaluation:}

The mean DISCERN score of the two raters for DISCERN was $63.4 \pm 11.3$ (38-80) (out of 80 possible points). The first rater and second rater had a mean DISCERN score of $63.5 \pm$ 11.3 (39-80, and $63.3 \pm 11.3$ (38-80), respectively. The intraclass correlation coefficient for the absolute agreement between the two raters was 0.996 (95\% Confidence Interval of 0.9938 to 0.9975$)$; this is regarded as an "excellent" reliability according to Cicchetti and Koo.(Cicchetti 1994; Koo and Li 2016; 2017)

The mean sum of the first 15 items of DISCERN was 59.3 (out of 75 total points). This is considered "good" quality of information (62-51 points).(Cassidy and Baker 2016)

The mean DISCERN score between the two raters for question 16 was 4.1 (2-5). The mean score for each individual rater was 4.1 (2-5) and 4.1 (2-5), respectively. This may be 
regarded as a "good" quality of information that is useful for patients making treatment choices. Specifically, 59 videos (73.75\%) scored a 4 or above indicating a good quality of publication.

The mean total DISCERN scores differed in regards to the uploader: patient videos scored the lowest at 47.64 while physicians videos uploads scored the highest at 68.11. Hospital videos scored 62.23 and educational channel videos scored 64.93.

Figure 3 illustrates the mean score for each of the 16 questions of DISCERN. Questions 1 to 3 scored the highest ratings overall. They pose essential questions in regards to qualitative video content: are the aims clear, does it achieve its aims, and is it relevant. Questions 4 to 8 all scored above 4, this is considered a "good" score. These five questions rate the publication based on the publication's clarity of sources of information, clarity of when the information was reported or used, bias, inclusion of additional sources, and uncertainty. The lowest scores were for questions 9 to 15. These questions are focused explicitly on treatment or lack thereof: how it works, what are the benefits, what are the risks, how they affect quality of life, and variety of treatments.

\section{Video Quality Correlations:}

Table 2 shows video quality in relation to the video content. Videos had a greater DISCERN score when they included: the results of the treatment $(P=0.0001)$, the prognosis $(P=$ $0.0001)$, the pathomechanisms $(P=0.0003)$, a doctor speaker $(P=0.0004)$ and diagrams $(\mathrm{P}=0.0098)$. 


\begin{tabular}{|c|c|c|}
\hline & With information & Without information \\
\hline & \multicolumn{2}{|c|}{ DISCERN } \\
\hline \multicolumn{3}{|l|}{ Results of treatment } \\
\hline Mean & 70.563 & 52.578 \\
\hline 95\% Confidence interval & 68.583 to 72.542 & 49.927 to 55.230 \\
\hline Sample size & 48 & 32 \\
\hline $\mathrm{P}$ value & \multicolumn{2}{|c|}{0.0001} \\
\hline \multicolumn{3}{|l|}{ Prognosis } \\
\hline Mean & 70.726 & 55.237 \\
\hline 95\% Confidence interval & 68.462 to 72.990 & 52.218 to 58.255 \\
\hline Sample size & 42 & 38 \\
\hline $\mathrm{P}$ value & \multicolumn{2}{|c|}{0.0001} \\
\hline \multicolumn{3}{|l|}{ Diagrams } \\
\hline Mean & 69.028 & 61.726 \\
\hline 95\% Confidence interval & 63.601 to 74.455 & 58.947 to 64.504 \\
\hline Sample size & 18 & 62 \\
\hline $\mathrm{P}$ value & \multicolumn{2}{|c|}{0.0098} \\
\hline \multicolumn{3}{|l|}{ Pathomechanism } \\
\hline Mean & 70.750 & 60.908 \\
\hline 95\% Confidence interval & 66.577 to 74.923 & 58.073 to 63.744 \\
\hline Sample size & 20 & 60 \\
\hline$P$ value & \multicolumn{2}{|c|}{0.0003} \\
\hline \multicolumn{3}{|l|}{ Doctor speaker } \\
\hline Mean & 67.395 & 59.726 \\
\hline 95\% Confidence interval & 63.870 to 70.919 & 56.409 to 63.043 \\
\hline Sample size & 38 & 42 \\
\hline $\mathrm{P}$ value & \multicolumn{2}{|c|}{0.0004} \\
\hline
\end{tabular}

Table 2: Statistically significant relationships between the DISCERN score and selected qualitative video content.

Optimization Analysis: 
Table 3 shows that audience engagement in relation to the video content. Videos that contained an animation $(P=0.034)$ or a doctor speaker $(P=0.0006)$ had a significantly higher average daily views and a higher VPI. There was a statistically significant relationship with a doctor speaker $(P=0.0005)$ in the video and a higher number of comments. There were no statistically significant findings in regards to the like ratio. 


\begin{tabular}{|c|c|c|}
\hline & With information & Without information \\
\hline & \multicolumn{2}{|c|}{ Average Daily Views } \\
\hline \multicolumn{3}{|l|}{ Animation } \\
\hline Mean & 940.60 & 408.74 \\
\hline 95\% Confidence interval & -123.84 to 2005.00 & 150.66 to 666.82 \\
\hline Sample size & 22 & 58 \\
\hline $\mathrm{P}$ value & \multicolumn{2}{|c|}{0.034} \\
\hline \multicolumn{3}{|l|}{ Doctor speaker } \\
\hline Mean & 218.29 & 859.64 \\
\hline 95\% Confidence interval & 34.57 to 402.01 & 242.71 to 1476.60 \\
\hline Sample size & 38 & 42 \\
\hline \multirow[t]{2}{*}{$\mathrm{P}$ value } & \multicolumn{2}{|c|}{0.0006} \\
\hline & \multicolumn{2}{|c|}{ Comments } \\
\hline \multicolumn{3}{|l|}{ Doctor speaker } \\
\hline Mean & 263.49 & 1096.2 \\
\hline 95\% Confidence interval & 98.331 to 428.64 & 591.16 to 1601.20 \\
\hline Sample size & 35 & 35 \\
\hline \multirow[t]{2}{*}{$\mathrm{P}$ value } & \multicolumn{2}{|c|}{0.0005} \\
\hline & \multicolumn{2}{|c|}{ Video Power Index } \\
\hline \multicolumn{3}{|l|}{ Animation } \\
\hline Mean & 914.33 & 402.77 \\
\hline 95\% Confidence interval & -126.14 to 1954.80 & 151.29 to 652.26 \\
\hline Sample size & 22 & 57 \\
\hline $\mathrm{P}$ value & \multicolumn{2}{|c|}{0.0489} \\
\hline \multicolumn{3}{|l|}{ Doctor speaking } \\
\hline Mean & 217.8 & 833.69 \\
\hline 95\% Confidence interval & 32.061 to 403.53 & 234.71 to 1432.70 \\
\hline Sample size & 37 & 42 \\
\hline $\mathrm{P}$ value & \multicolumn{2}{|c|}{0.0008} \\
\hline
\end{tabular}

Table 3: Statistically significant relationships between the average daily views, comments and the video power index against qualitative video content. 
Top quality YouTube videos:

\begin{tabular}{llll}
\hline DISCERN & Title & Uploader & YouTubeID \\
\hline 80 & $\begin{array}{l}\text { Bipolar Disorder: Treatment and Preventing } \\
\text { Relapse | Dr Patrick McKeon } \\
80\end{array}$ & Aware & LCeLKT2SFQo \\
Treatment of Bipolar Disorder & NAMI SGV & Q2KNgzVYQZo \\
\hline $\mathbf{8 0}$ & $\begin{array}{l}\text { Treatment Choices: Options for Bipolar } \\
\text { Disorder }\end{array}$ & DBSAlliance & gzgi9Sr7twY \\
\hline 79 & Treating Bipolar Disorder & Paul Merritt & wpYlrJ_ild0 \\
\hline 79 & Understanding and Treating Bipolar Disorder & freeCE & WfkgvBHPOYQ \\
\hline
\end{tabular}

Table 4: The top six highest quality bipolar disorder videos based on the DISCERN criteria

Table 4 shows the highest scoring YouTube videos. The three top scoring videos were tied with 80 points and the following 3 were tied with 79 points. The mean DISCERN score of the top six videos is 79.5 (99.375\%), which means patients may view them as a trusted source of health content. Half of the videos were uploaded by an educational channel, two were uploaded by hospitals and one was uploaded by a physician.

All these videos included the following five features: symptoms of BD, impact of the disorder on everyday life, results of treatment, discussion of prognosis and a doctor speaker. In general, these videos were 4 times longer in duration and (on average 4028 seconds in comparison to the average of all videos 1034) covered an entire gamut of information.

\section{Discussion}

\section{Quality Analysis:}

The overall quality and reliability of the bipolar videos varied, but most were of good quality. Thus, patients may gain the basic knowledge about BD on YouTube. Healthcare professionals have a duty to provide their patients with reliable medical information. Since it is impractical to peer-review all videos and other information on the internet, we have listed the top 6 highest quality videos on BD so that 
physicians may share reliable educational YouTube content to their patients over online communications (e.g. e-mail, social media, hospital websites). While there is research on other neuropsychiatric disorders on the internet and on YouTube, our paper is the first to cover an in-depth analysis on the quality and reliability of BD.

Our study shows that YouTube contains adequate medical information concerning BD. However, there were several factors which were often omitted, these included: the risks of each treatment, the consequences of treatment, the benefits of each treatment, how treatment would affect the overall quality of life, how each treatment works, and possibility of more than one treatment option. Future video creators may focus on these aspects as they are frequently omitted. Including this information would not only increase the quality of the videos, but also the popularity. We suggest that medical institutions tasked with publishing medical YouTube videos should consider our recommendations and use the DISCERN tool as a checklist for what should be included in their videos to provide a valid information package. We encourage hospitals to publish high quality and informative videos on BD and other medical topics.

\section{Optimization Analysis}

Prior studies found that patients do not engage with the highest quality educational videos.(Desai et al. 2013) Our study has comparable findings. Thus, it is critical for content creators (i.e. hospital staff and medical professionals) to understand what makes a video attractive and engaging to the viewer. This way, the most informative videos may be given attention instead of being ignored.

Our results show that videos containing an animation garnered the highest average daily views and VPI. This demonstrates that visual aids may make videos more appealing to viewers. The presence of a doctor speaker resulted in more comments, average daily views and VPI. This indicates that patients are more inclined to watch and interact with videos uploaded from a credible medical professional. This is a reassuring finding to know that patients appreciate or may be trying to reproduce the classical doctorpatient interaction on a digital interface. The presence of a patient experience was another determinant of high popularity indicating that patients value information coming from a relatable source.

\section{Context}

After deep analysis, the source of the videos with the highest popularity were more for entertainment purposes, especially news channels or other educational channels rather than hospitals. Media has a potent influence on the public perception of any kind of illnesses.(Ross et al. 2019; Young et al. 2008) Social media influencers should be mentioned as they can often outshine medical authorities in terms of traffic, views comments and popularity. Not to mention they profit from YouTube with ads and sponsorship deals.(Lindgren and Lundström 2019) There is no doubt that social media influencers often engage in mental health awareness as this is a popular topic among their viewers.(Belser Foster 2013) With the majority of YouTube users being between $15-25$ years old and $75 \%$ of mental health disorders 
being manifested before the age of 24 , it is understandable that mental health is a popular topic among this demographic.(Aslam; [CSL STYLE ERROR: reference with no printed form.])

Taking all this into consideration, it is evident that the risk of misconception is high since media coverage is bound to focus on details that create impact and interest. Therefore, it is of critical importance that health care institutions use media as a type of communication to provide accurate and high-quality information to the public. As noted previously, YouTube and other internet websites have gained more active role in the life of patients and in their management of illness or disease. During epidemics such as the recent novel corona pandemic, the role of telemedicine and online source of health information is emphasized even more. Doctors need to be aware of this and provide reliable resources for their patients. Previous YouTube quality studies found that physicians upload a relatively low number of educational or medical videos on YouTube.(Madathil et al. 2015; Szmuda et al. 2020b) Our study matches this finding as only $11.3 \%$ of the videos were published by physicians in our study. We encourage medical professions to use our optimization analysis findings to make their videos more appealing to the viewer.

Patients search the internet for medical information most often to learn about side effects from prescription drugs or to obtain help from coping with their disease.(Conell et al. 2016) This is especially important for patients with BD since the majority of them will inevitably turn to internet as a sources for health information.(Conell et al. 2016) Our study showed that videos often lacked information regarding how to cope with the disorder and what treatment they may undergo.

Patients and physicians may greatly benefit from empowering patients with un-biased and robust medical information. It has shown to reduce diagnostic times, create online support communities and encourage a more productive patient-doctor dialogue.(Madathil et al. 2015; Michalak et al. 2017; Naslund et al. 2014; Nour et al. 2017; Sangeorzan et al. 2019)

\section{Limitations:}

One may argue that a physician with experience with $\mathrm{BD}$, such as a psychiatrist, should be involved in the video evaluation process. However, the DISCERN instrument was created for "patients and information providers" and "was not dependent on specialist knowledge of a health condition or treatment". In addition, the two raters had an excellent intraclass correlation agreement indicating the quality analysis study was reliable and conclusive. Moreover, the two independent raters were medical students both having completed 90 hours of clinical rotations in psychiatry.

\section{Future Directions:}

Since this paper is a cross-sectional evaluation, we recommend that it be repeated within a few years to monitor alterations of video content quality. Such studies may focus on how physician and hospitalbased health channels on YouTube provide medical content based and if it up to date with recent evidence. Additional studies may be done to examine the extent to which patients with BD refer to 
YouTube specifically to gather information about their disease and whether they regard this information as valuable.

Since only English videos were analyzed future studies may focus the differences in video quality in various languages and geographical locations where there may be more stigmatization of mental diseases.(Botha et al. 2006)

\section{Conclusion}

YouTube is often a good source of information on BD as it fulfills basic information required for patient information. However, the quality of information may still improve particularly in regards to treatment risks, consequences, benefits and overall treatment options. The unregulated nature of YouTube means that videos may fail to meet a higher standard in conveying medical information. Thus, care should be taken by health professionals to provide reliable online information. We suggest that physicians reference our list of the highest quality videos on BD. Since a doctor speaker and animation significantly optimized a video for high audience engagement, we recommend that physicians create medical content on $B D$ and include animation in the video.

\section{Declarations}

ETHICS APPROVAL AND CONSENT TO PARTICIPATE: NOT APPLICABLE

CONSENT FOR PUBLICATION: NOT APPLICABLE

AVAILABILITY OF DATA AND MATERIAL: ALL DATA WAS AVAILABLE ONLINE

COMPETING INTERESTS: NOT APPLICABLE

FUNDING: NOT APPLICABLE

AUTHORS' CONTRIBUTIONS:

Szmuda, Tomasz- Methodology, Investigation, Formal analysis, Writing-original draft

Żydowicz, Weronika- Methodology, Investigation, Formal analysis, Writing-original draft

Ali, Shan- Methodology, Investigation, Formal analysis, Writing-original draft

Fedorow, Karolina- Methodology, Investigation, Formal analysis, Writing-original draft 
Słoniewski, Paweł- Writing-original draft

ACKNOWLEDGEMENTS: NOT APPICABLE

AUTHORS' INFORMATION :

Szmuda Tomasz MD, PhD; Medical University of Gdansk, Neurosurgery Department

Żydowicz Weronika; Medical University of Gdansk

Ali Shan; Medical University of Gdansk

Fedorow Karolina; Medical University of Gdansk

Słoniewski Paweł MD, PhD, Professor; Medical University of Gdansk, Neurosurgery Department

\section{References}

Aslam S. YouTube by the Numbers (2020): Stats, Demographics \& Fun Facts [Internet]. [cited $2020 \mathrm{Apr}$ 13]. Available from: https://www.omnicoreagency.com/youtube-statistics/

Belser Foster C. Mental Health On Youtube: Exploring the Potential of Interactive Media to Change Knowledge, Attitudes and Behaviors About Mental Health [Internet]. 2013. Available from:

https://scholarcommons.sc.edu/etd

Botha UA, Koen L, Niehaus DJH. Perceptions of a South African schizophrenia population with regards to community attitudes towards their illness. Soc. Psychiatry Psychiatr. Epidemiol. [Internet]. 2006 Aug [cited 2020 Apr 13];41(8):619-23. Available from: http://www.ncbi.nlm.nih.gov/pubmed/16733630

Cassidy JT, Baker JF. Orthopaedic Patient Information on the World Wide Web. J. Bone Jt. Surg. [Internet]. Lippincott Williams and Wilkins; 2016 Feb 17 [cited 2020 Mar 1];98(4):325-38. Available from:

http://journals.Iww.com/00004623-201602170-00012

Charnock D, Shepperd S, Needham G, Gann R. DISCERN: An instrument for judging the quality of written consumer health information on treatment choices. J. Epidemiol. Community Health. BMJ Publishing Group; 1999;53(2):105-11.

Cicchetti D V. Guidelines, Criteria, and Rules of Thumb for Evaluating Normed and Standardized Assessment Instruments in Psychology. Psychol. Assess. 1994;6(4):284-90. 
Conell J, Bauer R, Glenn T, Alda M, Ardau R, Baune BT, et al. Online information seeking by patients with bipolar disorder: results from an international multisite survey. Int. J. Bipolar Disord. SpringerOpen; 2016 Dec 1;4(1).

Desai T, Shariff A, Dhingra V, Minhas D, Eure M, Kats M. Is content really king? An objective analysis of the public's response to medical videos on YouTube. PLoS One. 2013 Dec 18;8(12).

Koo TK, Li MY. A Guideline of Selecting and Reporting Intraclass Correlation Coefficients for Reliability Research. J. Chiropr. Med. [Internet]. 2016 Jun [cited 2019 May 13];15(2):155-63. Available from: http://www.ncbi.nlm.nih.gov/pubmed/27330520

Lam NHT, Tsiang JTH, Woo BKP. Exploring the Role of YouTube in Disseminating Psychoeducation. Acad. Psychiatry. Springer International Publishing; 2017 Dec 1;41(6):819-22.

Lam NHT, Woo BKP. Efficacy of Instagram in Promoting Psychoeducation in the Chinese-Speaking Population. Heal. Equity [Internet]. 2020 Apr 1 [cited 2020 Apr 13];4(1):114-6. Available from: https://www.liebertpub.com/doi/10.1089/heq.2019.0078

Lindgren S, Lundström R. Tube therapy: Dealing with mental health problems in social video comment threads. First Monday [Internet]. 2019 May [cited 2020 Apr 13];24. Available from:

https://firstmonday.org/ojs/index.php/fm/article/view/9569/7788

Madathil KC, Rivera-Rodriguez AJ, Greenstein JS, Gramopadhye AK. Healthcare information on YouTube: A systematic review [Internet]. Health Informatics J. SAGE Publications Ltd; 2015 [cited 2020 Mar 8]. p. 173-94. Available from: http://www.ncbi.nlm.nih.gov/pubmed/24670899

Michalak EE, McBride S, Barnes SJ, Wood CS, Khatri N, Balram Elliott N, et al. Bipolar disorder research 2.0: Web technologies for research capacity and knowledge translation. J. Eval. Clin. Pract. Blackwell Publishing Ltd; 2017 Dec 1;23(6):1144-52.

Mileva VR, Vázquez GH, Milev R. Effects, experiences, and impact of stigma on patients with bipolar disorder. Neuropsychiatr. Dis. Treat. Dove Press; 2013 Jan 15;9(1):31-40.

Naslund JA, Grande SW, Aschbrenner KA, Elwyn G. Naturally occurring peer support through social media: The experiences of individuals with severe mental illness using you tube. PLoS One [Internet]. Public Library of Science; 2014 Oct 15 [cited 2020 Apr 13];9(10):e110171. Available from: http://www.ncbi.nlm.nih.gov/pubmed/25333470

Nour MM, Nour MH, Tsatalou OM, Barrera A. Schizophrenia on youtube. Psychiatr. Serv. [Internet]. American Psychiatric Association; 2017 [cited 2020 Apr 13]. p. 70-4. Available from: http://www.ncbi.nlm.nih.gov/pubmed/27524369

Rees CE, Ford JE, Sheard CE. Evaluating the reliability of DISCERN: a tool for assessing the quality of written patient information on treatment choices. Patient Educ. Couns. [Internet]. 2002 Jul [cited 2019 
May 13];47(3):273-5. Available from: http://www.ncbi.nlm.nih.gov/pubmed/12088606

Ross AM, Morgan AJ, Jorm AF, Reavley NJ. A systematic review of the impact of media reports of severe mental illness on stigma and discrimination, and interventions that aim to mitigate any adverse impact [Internet]. Soc. Psychiatry Psychiatr. Epidemiol. Dr. Dietrich Steinkopff Verlag GmbH and Co. KG; 2019 [cited 2020 Apr 13]. p. 11-31. Available from: http://www.ncbi.nlm.nih.gov/pubmed/30349962

Sangeorzan I, Andriopoulou P, Livanou M. Exploring the experiences of people vlogging about severe mental illness on YouTube: An interpretative phenomenological analysis. J. Affect. Disord. [Internet]. Elsevier B.V.; 2019 Mar 1 [cited 2020 Apr 13];246:422-8. Available from:

http://www.ncbi.nlm.nih.gov/pubmed/30599364

Shen H, Zhang L, Xu C, Zhu J, Chen M, Fang Y. Analysis of Misdiagnosis of Bipolar Disorder in An Outpatient Setting. Shanghai Arch. Psychiatry. Editorial Department of theShanghai Archives of Psychiatry; 2018 Apr 1;30(2):93-101.

Szmuda T, Özdemir C, Fedorow K, Ali S, Słoniewski P. YouTube as a source of information for narcolepsy: A content-quality and optimization analysis. J. Sleep Res. [Internet]. 2020a Apr 21 [cited 2020 Apr 23];e13053. Available from: https://onlinelibrary.wiley.com/doi/abs/10.1111/jsr.13053

Szmuda T, Rosvall P, Hetzger TV, Ali S, Słoniewski P. YouTube as a Source of Patient Information for Hydrocephalus: A Content-Quality and Optimization Analysis. World Neurosurg. [Internet]. Elsevier; 2020b Mar 5 [cited 2020 Mar 7]; Available from: https://www.ncbi.nlm.nih.gov/pubmed/32147561

Weil AG, Bojanowski MW, Jamart J, Gustin T, Lévêque M. Evaluation of the Quality of Information on the Internet Available to Patients Undergoing Cervical Spine Surgery. World Neurosurg. Elsevier Inc.; 2014;82(1-2):e31-9.

Young ME, Norman GR, Humphreys KR. Medicine in the popular press: The influence of the media on perceptions of disease. PLoS One. 2008 Oct 29;3(10).

Bipolar Disorder Statistics [Internet]. [cited 2020a Apr 15]. Available from:

https://www.dbsalliance.org/education/bipolar-disorder/bipolar-disorder-statistics/

Mental Health By the Numbers | NAMI: National Alliance on Mental Illness [Internet]. [cited 2020b Apr 13]. Available from: https://www.nami.org/learn-more/mental-health-by-the-numbers

iProspect Search Engine User Behaviour Study. 2006.

Social media "likes" healthcare [Internet]. 2012 Apr. Available from: https://www.pwc.com/us/en/industries/health-industries/library/health-care-social-media.html

Erratum to "A Guideline of Selecting and Reporting Intraclass Correlation Coefficients for Reliability Research" [J Chiropr Med 2016;15(2):155-163]. J. Chiropr. Med. [Internet]. 2017 Dec [cited 2019 May 
13];16(4):346. Available from: http://www.ncbi.nlm.nih.gov/pubmed/29276468

Global digital population 2020 [Internet]. 2020 [cited 2020 Apr 13]. Available from: https://www.statista.com/statistics/617136/digital-population-worldwide/

\section{Figures}

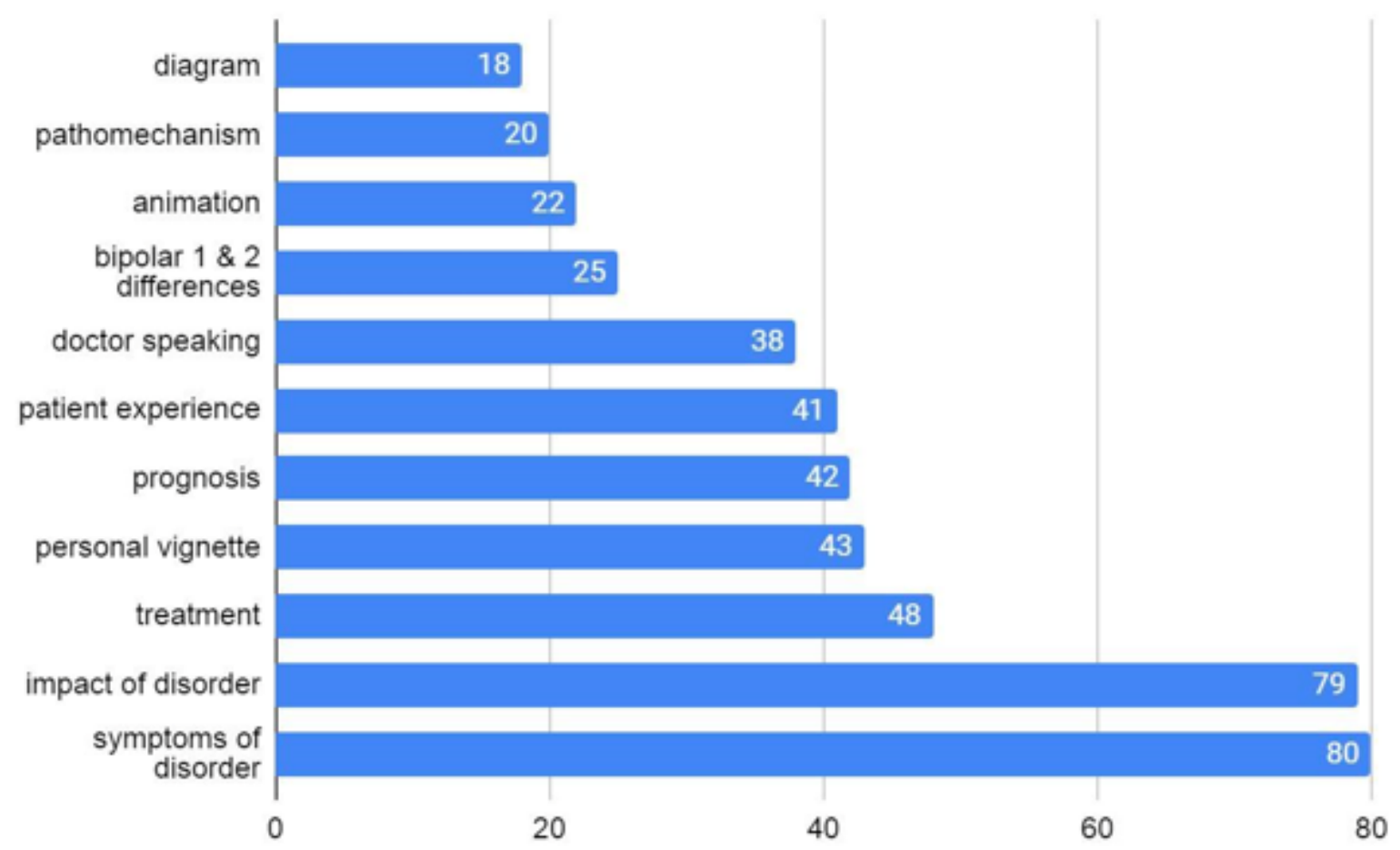

\section{Figure 1}

Qualitative content of videos about BD. 


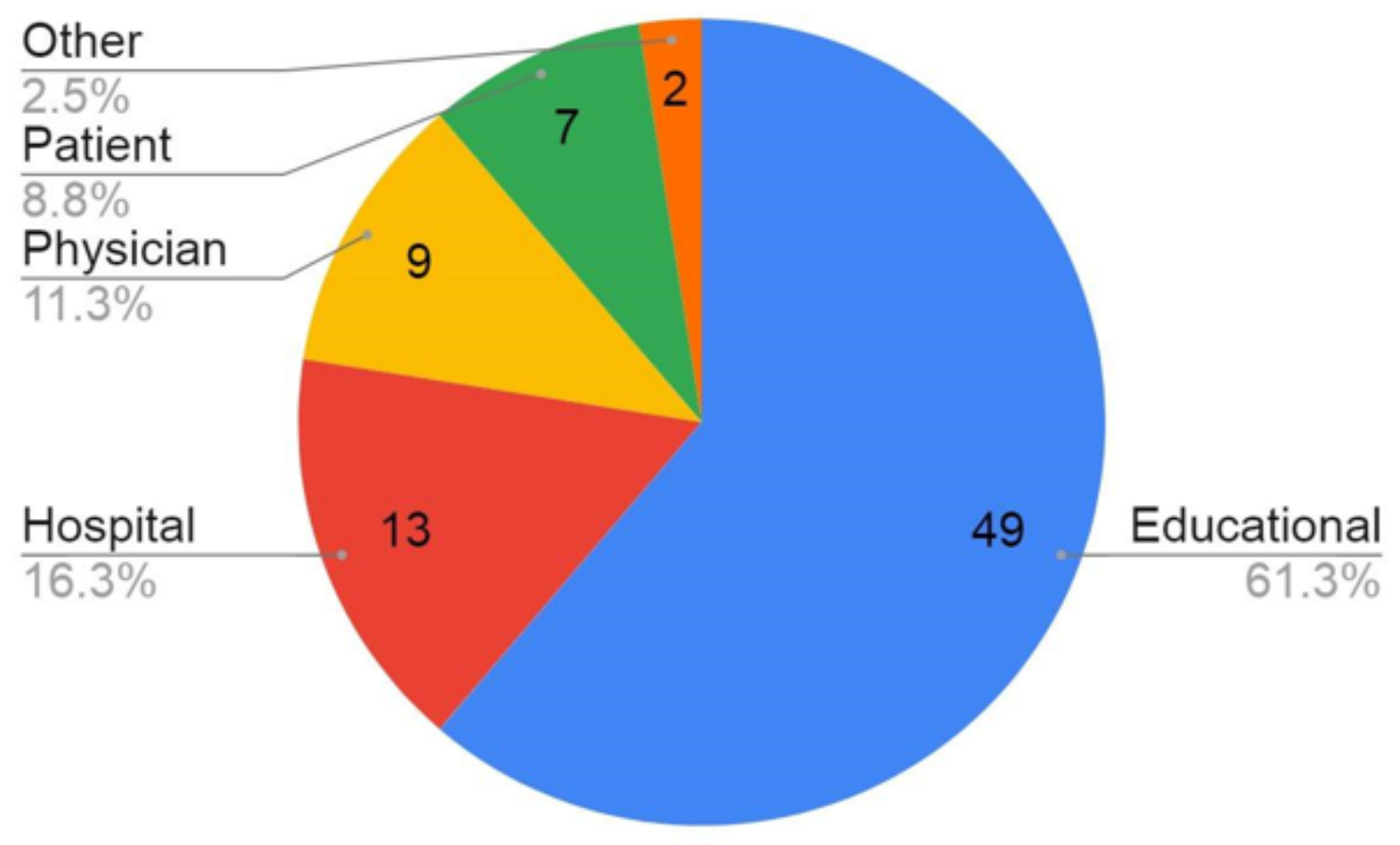

Figure 2

Source of the videos uploaded.

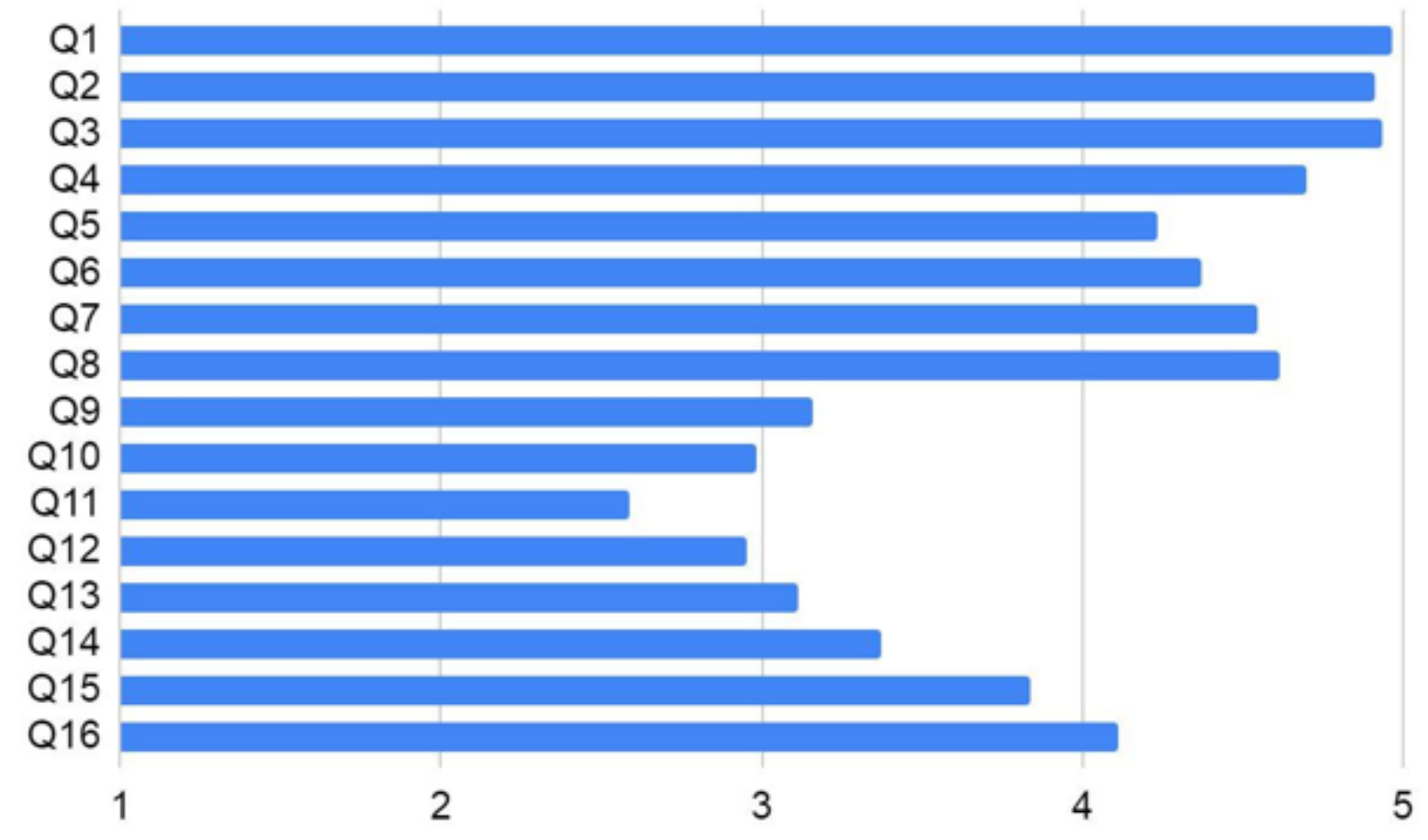

\section{Figure 3}

Mean score for each of the 16 questions of DISCERN. 